\title{
Where Lies the Answer? HIVIAIDS Prevention Campaign and the Rising Prevalence in South Africa
}

\section{Olusola Oyero}

\author{
Post-doctoral fellow, Department of Communication, North-West University, Mafikeng Campus, South Africa \& \\ Senior Lecturer, Department of Mass Communication, Covenant University, Ota, Nigeria. \\ Emails: 25799916@nwu.ac.za, \& olusola.oyero@covenantuniversity.edu.ng,
}

\author{
Abiodun Salawu \\ Professor, Department of Communication, North-West University, Mafikeng Campus, South Africa.
} Email. Abiodun.salawu@nwu.ac.za

Doi:10.5901/mjss.2014.v5n23p2026

\begin{abstract}
Despite the efforts at reducing the rate of HIV infection in South Africa, especially with the Khomanoni campaign in place, the country remains at a critical crossroads, with not only the largest HIV population in the world (6.4 million), but higher increase rate. The rising prevalence rate, which has increased from $10.6 \%$ in 2008 to $12.2 \%$ in 2012, calls for re-engagement of communication strategies in tackling the pandemic. This paper calls for a change in the application of the theoretical underpinnings of current HIV prevention communication strategies, which are usually KAPs based with condom use focused message. It advocates exploration of disciplined sexual lifestyle and emotional control strategies as necessary modification of message content towards a desirable behavioural change.
\end{abstract}

Keywords: HIVIAIDS, Knowledge, Emotion, Communication, Disciplined sexual life

\section{Introduction}

Behaviour Change Communication (BCC) is a process of promoting and sustaining health changes in individuals and communities through participatory development of appropriately tailored health messages and approaches that are conveyed through a variety of communication channels. In relation to HIV and AIDS, BCC focuses on the change from risky to non-risky health behaviours and practices. Towards this end, members of a community are given adequate knowledge in order to first understand the basic facts of HIV and AIDS. Then, they are made to develop favourable attitudes towards prevention, learn a set of skills, and have access to appropriate products and services.

In 2002, the South African government launched a mass media and social mobilisation campaign, the Khomanani Campaign, aimed at reducing new HIV infections and increasing the care and support for those infected and affected (Department of Health, South Africa, 2004). The Khomanani Campaign had six main themes; namely the Youth campaign, Circles of Support campaign, Positive Living campaign, STI campaign, Stop TB campaign and Health Worker Excellence campaign. The programme started with a baseline survey in 2002, followed by the full Khomanani Campaign in August and September 2002, and an evaluation survey to assess its success in 2003. The government has relaunched Khomanani campaign several time with several millions of Rands plunged into it. (South Africa Info, 2007, Nozipho Dlamini, 2007). Khomanani campaign was quite expansive and impressive. It consumed R125million in 2002; R190million in 2004; R270million in 2006; R543million in 2010, etc. (Blecher, 2011; Thom, \& Cullinan, 2010). It had audience reach of over 64\% as at 2009 and winning Public Sector Excellence Award by Brand Leadership Academy and recognition by Guinness World Book of Records for the mobilization campaign (Red Ribbon Challenge) (Sadmon, n.d.).

Despite the huge amount expended on Khomanani communication campaign, the gains there-from have been few. Since the start of the ARV roll-out in 2003, South Africa has made some incredible inroads, with the latest CDC data indicating an overall 25\% drop in new infections and a 50\% reduction in child HIV infections (the latter of which is largely due to highly effective mother-to-child interventions) (Sifris \& Myhre, 2014). However, the current situation testifies against any remarkable progress. The country remains at a critical crossroads, with not only the largest HIV population in the world (6.4 million), but higher increase rate. The rising prevalence rate has increased from $10.6 \%$ in 2008 to $12.2 \%$ in 2012. In 2012 alone, the Human Science Research Council (HSRC), reported 470,000 new diagnoses -- or nearly 1,100 
new infections every day. That is 100,000 more than was seen just one year earlier in 2011 (Shisana, 2014, p. 35). Driving these statistics is the decreasing, rather than increasing, public knowledge about HIV. According the HSRC report, only $26.8 \%$ of the 38,000 people surveyed understood how HIV was transmitted or ways to prevent it; that's down from $30.3 \%$ in 2008, with evidence showing that South Africans under 50 are having an increasing number of sexual partners and lower condom use. The current situation underscores the inevitability of reexamination of the state of communication campaign in the prevention of the pandemic and chatting a new way to make the campaign successful.

\section{Contextualizing HIVIAIDS Prevention Campaign in South Africa}

In South Africa, social and behavioral communication interventions are a critical component of HIVIAIDS prevention (Johnson et. al, 2010). There have been several rigorous communication campaigns implemented spreading all over the country by government agencies and nongovernmental organisations over the years (Shisana et. al, 2009). The purpose is to help combat the spread of HIV and AIDS by improving people's knowledge about modes of transmission, risk perceptions, changing sexual behaviours, questioning potential harmful social norms, and promoting resources and services that support prevention (Peltzer, at. al, 2012).

These campaigns have adopted various channels of communication such as the mass media (radio, television) and other interpersonal, community, and national channels to address prevention of HIVIAIDS (Kincaid \& Parker, 2008). Four major national-level HIV and AIDS communication programmes using mass media and other communication channels include Khomani, meaning "caring together;" LoveLife, which focuses mainly on teenagers, Soul City and Soul Buddyz which address adults and children, respectively, and the 46664 campaign which aims to promote HIV prevention through a series of events and activities linked to the ethos and values of Nelson Mandela.

There has been involvement in designing and implementing behaviour change communication (BCC) strategies using information, education and communication aim at promoting comprehensive HIV-prevention messages and delivering these messages to specific audiences with the aim of changing health-related behaviour. Also is the implementation of community-oriented behaviour change which recognises that behaviour change occurs in a context of social change. Information is placed within communities to facilitate dialogue, debate and collective action. This approach recognises the importance of creating widespread awareness about the range of behaviours that are necessary.

The various strategies employed have focused on the cognitive self-agency models of action as means towards behaviour change.

\subsection{Health Belief Model}

The Health Belief Model (HBM) is a psychological model that attempts to explain and predict health behaviour. This is done by focusing on the attitudes and beliefs of individuals. The model was developed in response to the failure of a free tuberculosis (TB) health screening program. Since then, the HBM has been adapted to explore a variety of long- and short term health behaviours, including sexual risk behaviours and the transmission of HIVIAIDS. The HBM is based on the understanding that a person will take a health related action (i.e., use condoms) if that person: (1)feels that a negative health condition (i.e., HIV) can be avoided, (2) that he/she has a positive expectation that by taking a recommended action, he/she will avoid a negative health condition (i.e., using condoms will be effective at preventing HIV), and (3) believes that he/she can successfully take a recommended health action (i.e., he/she can use condoms comfortably and with confidence). The HBM was spelled out in terms of four constructs representing the perceived threat and net benefits: perceived susceptibility, perceived severity, perceived benefits, and perceived barriers (Glanz \& Rimer, 1997).

\subsection{Theory of Reasoned Action/Theory of Planned Behaviour}

This theory provides a framework to study attitudes toward behaviours. It suggests that performance of a given behaviour is primarily determined by the intention to perform that behaviour. In other words, the most important determinant of a person's behaviour is behaviour intent. The individual's intention to perform behaviour is a combination of attitude toward performing the behaviour and subjective norm. The individual's attitude toward the behaviour includes; behavioural belief, evaluations of behavioural outcome, subjective norm, normative beliefs, and the motivation to comply.

If a person perceives that the outcome from performing behaviour is positive, she/he will have a positive attitude toward performing that behaviour. The opposite can also be stated if the behaviour is thought to be negative. If relevant others see performing the behaviour as positive and the individual is motivated to meet the expectations of relevant others, then a positive subjective norm is expected. If relevant others see the behaviour as negative and the individual 
wants to meet the expectations of these "others", then the experience is likely to be a negative subjective norm for the individual. The intent to perform a behaviour depends upon the product of the measures of attitude and subjective norm. A positive product indicates behavioural intent (Glanz, \& Rimer, 1997). TRA works most successfully when applied to behaviours that are under a person's volitional control. If behaviours are not fully under volitional control, even though a person may be highly motivated by her own attitudes and subjective norm, she may not actually perform the behaviour due to intervening environmental conditions. The Theory of Planned Behaviour (TPB) was developed to predict behaviours in which individuals have incomplete volitional control.

The major difference between TRA and TPB is the addition of a third determinant of behavioural intention, perceived behavioural control. Perceived Behavioural control is determined by two factors: Control Beliefs and Perceived Power. (Madden \& Ajzen,1992). Perceived behavioural control indicates that a person's motivation is influenced by how difficult the behaviours are perceived to be, as well as the perception of how successfully the individual can, or cannot, perform the activity. If a person holds strong control beliefs about the existence of factors that will facilitate a behaviour, then the individual will have high perceived control over a behaviour. Conversely, the person will have a low perception of control if she holds strong control beliefs that impede the behaviour. This perception can reflect past experiences, anticipation of upcoming circumstances, and the attitudes of the influential norms that surround the individual.

\subsection{Social Cognitive Theory (SCT)}

Social Cognitive Theory (SCT) describes a dynamic, ongoing process in which personal factors, environmental factors, and human behaviour exert influence upon each other. According to SCT, three main factors affect the likelihood that a person will change a health behaviour: (1) self-efficacy, (2) goals, and (3) outcome expectancies. If individuals have a sense of personal agency or self-efficacy, they can change behaviours even when faced with obstacles. If they do not feel that they can exercise control over their health behaviour, they are not motivated to act, or to persist through challenges. As a person adopts new behaviours, this causes changes in both the environment and in the person. Behaviour is not simply a product of the environment and the person, and environment is not simply a product of the person and behaviour. SCT evolved from research on Social Learning Theory (SLT), which asserts that people learn not only from their own experiences, but by observing the actions of others and the benefits of those actions (Bandura 1986). Bandura updated SLT, adding the construct of self-efficacy and renaming it SCT. (Though SCT is the dominant version in current practice, it is still sometimes called SLT.) SCT integrates concepts and processes from cognitive, behaviourist, and emotional models of behaviour change, so it includes many constructs. It has been used successfully as the underlying theory for behaviour change in areas ranging from dietary change to pain control.

The conception in the cognitive based models above is that individual intention provides the motivation for human action (Nzioka, 1996). The models assume that an individual's decision whether or not to engage in preventative behaviour, is based upon the perception of the risks and of the advantages and disadvantages that the individual may derive from a protective act (Valdiseseri, 1989, cited in Kelly, Parker \& Lewis, 2001, p.13). So, the models see individual cognitive rational decision making based on the perceived costs and benefits of risk-related action as the determinant of and behaviour change. Individuals are seen as transformers of information, "with their pre-existing conceptions acting as filters through which information is interpreted and given significance" (Bajos et al., 1997, p.25).

This is exactly what informed the condom use persuasion as the dominant content in HIV prevention messages. The assumption is that developing the intention to use condom, with the awareness of the risks involved in unprotected sex will translate into actual use, which will lead to the achievement of the goal of prevention of HIV. As such, the dominant message of HIV communication prevention has been that of behavioural change from engagement in unprotected sex to protected sex through the use of condom.

\section{The Current Dilemma}

The current prevalence of HIV despite several interventions and huge amount expended on prevention is a big challenge. It is clear that the efforts made so far have not yielded the desired result; hence, the need to look at different direction for possible intervention to solving the problem. The problem with HIVIAIDs prevention communication is not with the adopted models of the campaign but the misapplication of those theories. The actual issue with the spread of HIVIAIDS in South Africa is primarily attributable to promiscuous lifestyle and secondarily to failure of condom use strategy for prevention of the pandemic. It is a general knowledge that of all the means of contracting HIV, contraction through sexual means (over 90\%) tops the list for the spread of the disease (Gouws, White, Stover \& Brown, 2006). 


\subsection{Promiscuous Lifestyle}

In South Africa, like other parts of the world, the sexual lifestyle of many people is disgraceful. In a national survey conducted in 2012, whose report was made available in 2014, one tenth of respondents admitted to have had sex for the first time before the age of 15 years. Three times more males than females reported having sex for the first time before the age of 15 years and 19.8\% young people aged 15-24 years (male and female) had a sexual partner who was 5 years older (Shisana, et al, 2014: 65). To worsen the situation, in January 2013, consensual sexual acts between children aged 12 and 16 years old were legalised by a Pretoria High Court (SABC, 2013), a situation that might lead to greater increase in engagement in sexual activities and the attendant increase in sexually transmitted diseases.

The report further says that $12.6 \%$ of respondents reported having been involved with multiple sexual partners in the last 12 months, with a percentage five times higher found among males than among females. There is an inverse relationship between age and multiple sexual partnerships with a higher percentage of younger respondents reporting that they have had more than one sexual partner in the past 12 months compared to older respondents. Black Africans reported the highest percentage of respondents who have had more than one sexual partner in the past 12 months compared to the other race groups (Shisana, et al, 2014: 69-70). With respect to trend analyses, there was a steady increase in the rates of multiple sexual partnerships from 11.5\% to 18.3\% between 2002 and 2012 respectively. Another statistics by the Soul City OneLove Campaign shows $45 \%$ of males aged $15-19$ and $28 \%$ of women of the same age have multiple and concurrent intimate partners, while $36 \%$ of $20-24$ year old males and $21 \%$ of the women in the same category also embrace this risky sexual behaviour (Hadebe, n.d.).

Makhubele's (2007) study on Risk and Sex in an HIV Epidemic gave an insight into the sex behaviour of people. He conducted interviews and focus group discussion to understand the sexual behaviour of people in Eastern Cape, Gauteng, Northern Cape, Western Cape and Mpumalanga. The findings show that people engage in multiple sexual relationships most of which are casual, within short moment of contact. There is a strong peer influence to engage in sex and people have wrong conception of faithfulness, trust and honesty.

Makhubele explains that people get involved in multiple partnerships for fear of being disappointed when involved with one partner and some do it to get temporary satisfaction when the need arises and for lack of personal discipline. One of the responses obtained by Makhubele goes thus:

What can I say? I was losing control over myself. I was unable to control my feelings and ended up agreeing to different men's propositions at the same time... How can I say this? Maybe I love that person while I am involved with another one. It is difficult for me to say no to the person I love, so I end up saying yes.

(Female, 21, Eastern Cape)

The study further shows that having a married partner was seen as having a relationship with someone who was 'honest' and less likely to stray than a person who was single. Besides, the concept of faithfulness was not understood as having an exclusive relationship. Rather it had to do with protecting one's partner from 'hurt'. A respondent says:

Being faithful is protecting the one you love from hurt. You make sure that he only knows the best about you and you give him the best love. The others are just there when he is not around, to keep you company.

As for me, I have my girlfriend, the one that I spend most of my time with. I am faithful to her because even when I have other girlfriends I do not walk around with them for her to see me. I hide the other girlfriends.

(FGD, Male, 20-30, Gauteng)

There are also those who get involved in multiple sexual partnerships due to peer pressure as one of the respondents says:

Like when you don't have many girlfriends it is like you are a moshemane (boy). Things like that. They will say you are gay or something. They can mock you. Interviewer: And if they see you with a whole lot of different girls? Interviewee: They will say 'haai, uyinja wena' (you are a top dog)! You are the man. (Male, 18, Gauteng)

Makhubele's study is an exposition on people's orientation and beliefs about sex. Whatever people believe will influence their attitudes and behaviours. As earlier noted, sexual practices are the major cause of the spread of HIVIAIDS, it follows to say further that as long as people throw caution to the wind and continue to engage in illicit sexual practices, the spread of HIVIAIDS may be aggravated. 


\subsection{Failure of Condom Use Strategy}

The HIV prevention message traditionally follows the ABC pattern- Abstinence, Be faithful to one partner and Condomise (Use Condom). Unfortunately, the emphasis of HIV prevention messages has always been the use of condom while abstinence and faithfulness are downplayed. The government and many non-governmental organisations have also ensured that condoms are provided to the generality of the people as they want. A total of 439 million male condoms and over 3 million females were distributed between 2006 and 2007, and 450 million condoms were distributed in 2012 (DeCapua, 2012). The dysfunctional aspect of this to HIV prevention campaign is that more people are indirectly encouraged to be involved in illicit sex with availability of condoms around while the message of abstinence is almost non-existent. In fact, children and young people would ordinarily be tempted to try out the use of condom since this is the message that pervades the airwaves and billboards. Besides, the scenic atmosphere around which the message of condom is built tends to show some romantic moods- you see a young man caressing a lady, and the condom idea 'drops'. Thus the message does not in any way teach about abstinence but condom use.

Unfortunately, condom does not offer a 100 per cent guarantee from contracting HIV. Food and Drug Administration (FDA) (n.d.) of the United States notes that condom use cannot provide absolute protection against any STD. The most reliable ways to avoid transmission of STDs are to abstain from sexual activity, or to be in a long-term mutually monogamous relationship with an uninfected partner. While body of research on the effectiveness of latex condoms in preventing sexual transmission of HIV is both comprehensive and conclusive and that the ability of latex condoms to prevent transmission of HIV has been scientifically established in "real-life" studies of sexually active couples as well as in laboratory studies (National Institute of Allergy and Infectious Diseases, 2001; Holmes, Levine \& Weaver, 2004).), many other factors have made condom use insufficient as instrument to prevent HIV.

Sometimes, there are problems with condom that people use. One is the wrong or improper use of condom thus making the user predisposed to be infected. When condom is not used as prescribed, apparently human error that is inevitable in human activities, the functionality is affected. There have been cases of manufacturing problem with condoms. Though efforts are made in such instances to recall the batches of such condom just like 2007 and 2012 South African experience where over 20 million and 1.35 million condoms respectively were recalled (Faul, 2012), but the truth is that some users may have been affected in the process before recall. Condoms could also undergo deterioration during shipping, handling and storage, and even further degradation after purchase by the end user. Besides, other factors such as exposure to sunlight, heat (including body heat when placed in pockets or wallets), humidity, pressure, certain spermicides and even to atmospheric could contribute to the degradation of latex and thus to condom failure (Baker, Sherwin, Bernstein \& Nakamura, 1988). Again, some condoms are not genuine or do not offer the same kind of protection for the prevention of HIV; when people use these kinds of condoms, they fall victim of the pandemic. All of these challenges with condom are never indicated when messages about HIVIAIDS are churned out, but instead, condom is usually presented as the "almighty saviour" from infection of HIV. It is in this regard that Salawu (2004, p.46) calls for interrogation of HIV prevention edutainment campaigns if they really meet their objectives or people are just being entertained and being successfully pushed to buy more condoms.

Thus far, the contents of HIVIAIDS prevention messages have been contradictory. Majority of HIV messages are based on condom use while few others discourage involvement in casual and multiple sexual partnerships. When these two types of messages co-exist on the same subject, it undermines the expected impact of the campaign. This is evident in a question that a teenage boy asked during a youth conference some years ago. He asked a question in relation to a radio jingle on HIV prevention which ends with a statement in Pidgin English: "... if you no fit hold body, use condom"; that is if you cannot control your body, use condom. He wants to know why he should make effort at all to control his body since there is another way out (Success Academy for Youth, 2001). Examining five common HIVIAIDS communication brands that have been adopted to combat HIV pandemic in South Africa, namely: Khomanani Campaign, Soul City Campaign, Love Life Campaign, Scrutinize Campaign and the Siyayinqoba Beat It Campaign (Mpofu, 2014), messages on delayed sexual activity and avoidance of multiple sexual partnership co-exist with that of condoms and contraceptives use.

Another factor that has hindered the workability of condom is the emotional nature of sex. Though one may possess the knowledge that condom use can reduce the rate of HIV infection, and so should be used when involved in the act, the possibility of emotion overriding that knowledge is one that cannot be ruled out. Kelly, Parker and Lewis (2001) buttress this point by noting that "Approaches to risk reduction such as condom use also have limitations, even where sexual partners are highly motivated to use them,... the immediacy of sexual desire may overwhelm intentional use..." (Kincaid, Parker, Schierhout, Connolly \& Pham, 2008: 6). Similarly, Kelly, Parker and Lewis (2001, p.14) notes: 
we do not necessarily make cognitive risk assessments when we make HIV risk reduction decisions. In the throes of an unexpected and coercive sexual encounter, or in being deceived by a partner about his/her previous sexual history, one's health beliefs have little effect in determining outcome. But even in cases where we have greater capacity to influence levels of risk avoidance, and where we successfully do so, decisions may 'come upon us.

Health belief model posits that a person will take a health-related action such as the use of condoms if that person feels that a negative health condition (i.e., HIV) can be avoided, has a positive expectation that by taking a recommended action, he/she will avoid a negative health condition (i.e., using condoms will be effective at preventing HIV), and believes that he/she can successfully take a recommended health action (i.e., he/she can use condoms comfortably and with confidence). To the contrary in many situations, people become overwhelmed by sexual urge and could not practice what they know. McPheat (2010) tries to explain the interplay between rationality and emotion and why the situation described above evolves:

When external stimuli are received through one of our five senses, the signal is sent to the thalamus and translated into the brain's language of chemical thought.... If the correct response involves an emotion, the signal is sent on to the amygdala, the brain's emotional center. But at the same time that most of the signal is sent to the rational area of the brain for processing, a portion of it is sent straight to the amygdala, before the brain has the chance to cognitively process the signal. In other words, a strong enough signal from our senses will trigger an immediate emotional response before we've been able to rationalize how we should respond (p. 13).

The reality from the above is that, most times, emotion is more powerful than knowledge, the reason why people lose control in many circumstances including involvement in unprotected sex even when they are aware of the possible consequences.

\section{HIV Prevention Communication and Theoretical Refocusing}

The central goal in HIVIAIDS communication campaign is to prevent new infection of the disease through change in pattern of behaviour. Having established the factors responsible for rising level of the disease, the campaign towards prevention should gear towards evolution of a new cultural lifestyle that embraces sexual discipline. Indiscriminate sexual practice is the major cause of HIVIAIDS prevalence, making people to change their behaviour in this regard should be the central focus of communication campaign. The challenge with current HIV prevention communication which is condomuse based is that it does not address the actual cause of the problem. In other words, people should be educated to lead a disciplined sexual life that prevents pre-disposition to the risk of HIV.

The idea of disciplined sexual life is in tandem with ethical paradigm which involves cultivation of mind for the higher ideas of the society (Salawu, 2011). It embraces peace, good health, abundance and progress of the society. Communicating to combat HIVIAIDS therefore should focus on promoting higher ideal of disciplined sexual life. This is what Oyero (2007) also refers to as psycho-management paradigm of development when he notes that myriads of problems confronting Africa can only be surmounted through management of minds of Africans towards a new orientation, attitudinal change, and change in values system. Oyero (2007) identified values of honesty, diligence, excellence and self-determined action as necessary to overcoming many Africa's problems. Salawu $(2011$, p.19) also notes that virtues of good conduct, altruism, hardwork, productivity, fairness and honesty are not strange to Africa as they are part of the original African spirit, and therefore should be rekindled to confront Africa's challenges.

A disciplined sexual life entails a consciousness of the risk of HIV and deliberate decisions to avoid risky practices such as casual and multiple sexual practices which are the dominant cause of the spread of the infection. The pervasive sex culture, outside child bearing and the pleasure of marriage relationship, that encourages woman's right to choose abortion, thus making it legally possible to be rid of the natural fruit of the sexual act, and the rise of homosexual-rights movement (Fagan, 1998), presents a cultural environment for future generation to follow which is counter-productive to the HIV prevention campaign. Therefore, that culture needs to change to promoting discipline rather than a slippery survival strategy of condom use which has not really worked.

Moreover, the idea of sexual discipline should not be viewed as unattainable or impossible. Every successful endeavour in life demands discipline; such is the quest to overcome the HIV pandemic. Many people have said a lot about the importance of discipline. Gary Ryan Blair says "Self-discipline is an act of cultivation. It requires you to connect today's actions to tomorrow's results. There's a season for sowing a season for reaping. Self-discipline helps you know which is which (Brian Quotes n.d). Ross Perot also points out the importance of self-discipline by saying that "you will need a great deal of self-discipline not to lose your sense of balance, humility, and commitment." Israelmore Ayivor 
cautions against anything that could bring adverse consequences, "No matter how sweet it smells, if you know it will give you a discomfort later, don't even attempt to taste it. Discipline yourself to stay out...!"(Goodread, n. d.) While it will definitely not be easy, it is worth all the efforts. It is in this regard that Charles Glassman says "Self-discipline is often disguised as short-term pain, which often leads to long-term gains. The mistake many of us make is the need and want for short-term gains (immediate gratification), which often leads to long-term pain." (Goodread, n.d). The Holy Writ crowns this thought by saying, "Like a city whose walls are broken through is a person who lacks self-control" (Proverbs 25, verse 28, New International Version).

The sexual revolution can be made possible through the cultivation of emotional intelligence. Emotional intelligence is not the opposite of intelligence, it is not the triumph of heart over the head, it is the unique intersection of both' (David Caruso, cited in McPheat, 2010: 25) and the ability to manage one's self. The principles, which incorporate discipline, include the following:

(1)Self-control is the ability to refrain from knee-jerk reactions in response to one's emotions. It requires the ability to stop, consider the best decision to take and take responsibility for one's emotions. There must be continuous personal reflections on actions to take in circumstances; reframing or altering one's reactions to a given emotion through self-talk in that direction and to mentally prepare for action to take in order to manage one's emotion properly. (2)Trustworthiness: This involves managing one's self to do what one says and being honest about what one can and cannot do. (3)Conscientiousness- (commitment): This means to be alert and committed to managing one's self and taking responsibility for one's emotions. (4)Adaptability: This requires that one tries to adjust to the new decisions taken about change being made in one's lifestyle. One must constantly justify the change being made and assure one's self that it is desirable. (5)Initiative: This has to do with looking for ways to continually develop oneself in the process of staying stable in self-discipline and avoiding lustful tendencies that can lead to illicit sexual relationship. (6)Possibility mentality: This entails developing a mindset that the desire change is possible and sustainable. This will instill self-confidence and inner assurance in staying stable in the face of overwhelming emotional circumstances.

The idea of disciplined sexual life can then be properly propagated using the same once misapplied theoretical models adopted for condom use messages. For example, looking at the health belief model which posits that intention to use condom will lead to eventual use, it follows then that a person will take a health related action (i.e., disciplined sexual life style) if that person: (1)feels that a negative health condition (i.e., HIV) can be avoided, (2) that he/she has a positive expectation that by taking a recommended action, he/she will avoid a negative health condition (i.e., avoiding casual and multiple sexual relationship will be effective at preventing HIV), and (3) believes that he/she can successfully take a recommended health action.

Similarly, theory of reasoned action says that if a person perceives that the outcome from performing behaviour is positive, she/he will have a positive attitude toward performing that behaviour. The opposite can also be stated if the behaviour is thought to be negative. We can then follow that logic that if a person perceives that the outcome of living a disciplined sexual life is favourable, he/she will have a positive attitude toward performing that behaviour (i.e. being sexually disciplined).

The principles outlined in social cognitive theory are very germane in theoretical refocusing of HIV prevention communication. Three main factors affect the likelihood that a person will change a health behaviour are self-efficacy, goals, and outcome expectancies. If an individual has a sense of personal agency or self-efficacy, s/he can change behaviours about sexual practices even when faced with obstacles. If s/he does not feel that s/he can exercise control over his/her health behaviour, s/he is not motivated to act, or to persist through challenges. As a person adopts new behaviours, this causes changes in both the environment and in the person. Behaviour is not simply a product of the environment and the person, and environment is not simply a product of the person and behaviour. In line with these principles, it follows that HIV prevention messages can be packed to build people's self-efficacy so that they can have motivation to live a disciplined sexual life by believing that they can exercise control over their sexual behaviour.

Social cognitive theory, rooted in social learning theory (Bandura,1986) emphasizes the influence of the environment on behaviour asserting that people learn not only from their own experiences, but by observing the actions of others and the benefits of those actions. This underscores the relevance of a culture of sexual discipline. Instead of the culture of condom use, the culture of sexual discipline, abstinence and faithfulness should be encouraged to engender healthy lifestyle among people.

\section{Conclusion}

The situation with HIV and its impact on society and the future generation of a nation is one that requires a revolutionary idea, such as expressed in this paper. No matter how we shy away from reality, it will always exist. Considering several 
efforts that have been made towards reducing the impact of HIVIAIDS without achieving the desired result, it is time we adopted a different approach to countering the pandemic. While the theoretical approaches to communicating about HIVIAIDS remain, the message content would have to change, a change from propagating condom use which indirectly encourages loose sexual behaviour (the actual major cause of the disease) to adopting a culture of self-discipline in sexual practices. Except people change sexual behaviour through being sexually disciplined and applying emotional intelligence, the HIV- Free Generation vision will be a utopian one. This should be the direction of HIV prevention communication campaign.

\section{References}

Bajos, N., Ducot, B., Spencer, B., Spira, A. \& ACSF Group (1997). Sexual risk-taking, socio-sexual biographies and sexual interaction: Elements of the French national survey on sexual behaviour. Journal of Social Science and Medicine, 44, 25-40.

Baker, R. F. Sherwin, R. Bernstein G. S. \& Nakamura, R. M. (1988). Precautions When Lightning Strikes During the Monsoon: The Effect of Ozone on Condoms. Journal of American Medical Association. 260 (10): 1404-1405.

Bandura, A. (1986). Social Foundations of Thought and Action. Englewood Cliffs, New Jersey: Prentice-Hall.

Blecher, M. (2011, June 30). Appropriations committee presentation: Health and social development. National Treasury, South Africa

Brian Quotes (n.d). Self-discipline. Accessed June 13, 2014 from http://www.brainyquote.com/quotes/keywords/self-discipline.html\# bJldfJc7ofJdoMld.99

Centers for Disease Control and Prevention (CDC). (2004) Rev. Vol. 16. Atlanta, GA: US Department of Health and Human Services, CDC; 2006. HIV/AIDS surveillance report,. Availableat:http://www.cdc.gov/hiv/topics/surveillance/resources/reports/2004report/ default.htm. Accessed 8 March 2007.

Congress of South African Trade Unions (COSATU). COSATU Booklet on the Campaign Against HIV I AIDS Accessed May 20, 2014 from http://www.cosatu.org.za/show.php?ID=1474

DeCapua, J. (Voice of America July 24, 2012) http://www.voanews.com/content/aids-2012-saf-survey-24jul12/1444352.html

Department of Health, South Africa. (2004). Moving the nation to act. A research report on the Khomanani Campaign 2001-2004. Pretoria: Department of Health

Do, M., L. D. Kincaid, and M. E Figueroa, "The joint effects of 11 communication programs on HIV testing in South Africa: An application of multiple causal attribution analysis. Poster Presentation," in Proceedings of the 19th International AIDS Conference, Washington, DC, USA, July 2012.

Education Training Unit (ETU) (n.d.) HIV and AIDS Campaign Guide http://www.etu.org.za/toolbox/docs/organise/webaids.html

Fagan, P. F. (1998, November,)."A 'Culture'of Inverted Sexuallty." Catholic World Report. Accessed May 25, 2014 from http:/l catholiceducation.org/articles/sexuality/se0049.html

Faul, M. (2012, January 31, Huff Post Healthy Living). Condom Recall: South Africa Recalls 1.35 Million Prophylactics. Accessed June14, 2014 from http://www.huffingtonpost.com/2012/01/31/condom-recall-south-africa_n_1243449.html

Food and Drug Administration (FDA)(n.d.). Condoms and Sexually Transmitted Diseases. Accessed May 7, 2014 from http://www.fda.gov/forconsumers/byaudience/forpatientadvocates/hivandaidsactivities/ucm126372.htm

Glanz, K., Lewis, F. M. \& Rimer, B.K. (1997). Theory at a Glance: A Guide for Health Promotion Practice. National Institute of Health.

Goodread (n.d) Quotes About Self Discipline. Accessed June 13, 2014 from http://www.goodreads.com/quotes/tag/self-discipline

Gouws, E., White, P. J., Stover, J. \& Brown, T. (2006). Short term estimates of adult HIV incidence by mode of transmission: Kenya and Thailand as examples. Sex Transm Infect. 82(Suppl 3) iii51-5.

Hadebe, Z. (n.d.). High risk sexual behaviour of youngsters.http://www.lovelife.org.za/corporate/press/news/high-risk-sexual-behaviourof-youngsters/

Holmes, King K., Levine, Ruth, \& Weaver, Marcia. (2004). Effectiveness of condoms in preventing sexually transmitted infections. Bulletin of the World Health Organization, 82(6), 454-461. Retrieved June 06, 2014, from http://www.scielosp.org/scielo.php? script=sci_arttext\&pid=S0042-96862004000600012\&lng=en\&thng=en. 10.1590/S0042-96862004000600012.

IoL News, 2010) SA teens' sexual behaviour revealed. May 132010 at 05:52pm. http://www.iol.co.za/news/south-africa/sa-teens-sexualbehaviour-revealed-1.483841\#.U3Yd2CiKT8U

Johnson S, Kincaid L, Laurence S, Chikwava F, Delate R, \& Mahlasela L. (2010). Second National HIV Communication Survey 2009. Pretoria, South Africa: JHHESA;

Kelly, K. Parker, W. \& Lewis, G. (2001). Reconceptualising behaviour change in the HIVIAIDS context. In Stones, C. (Ed .), Sociopolitical and psychological perspectives on South Africa. Nova Science, London: Centre For Aids Development, Research And Evaluation http://www.cadre.org.za/files/Reconceptualising_BC_Kelly.pdf

Kincaid, D. L. \& Parker, W. (2008).National AIDS Communication Programmes, HIV Prevention Behaviour, and HIV Infections Averted in South Africa, 2005, JHHESA, Pretoria, South Africa,

Kincaid, D.L., Parker, W., Schierhout, G., Connolly, C., \& Pham, V.H.T. (2008). AIDS Communication Programmes, HIV Prevention, and Living with HIV and AIDS in South Africa, 2006. Pretoria: JHHESA.

Madden, M. J.; Ellen, P. S.; Ajzen, I. (1992). A Comparison of the Theory of Planned Behaviour and the Theory of Reasoned Action. Personality and Social Psychology Bulletin, 18 (1), 3-9.

Makhubele, M. B. (2007). Risk and sex in an HIV epidemic: Challenges for HIV prevention communication. Gauteng AIDS Conference 
2007. Centre For Aids Development, Research and Evaluation

McPheat, S. (2010).Emotional Intelligence: MDT Training. Available at http://bookboon.com/en/emotional-intelligence-ebook\#download

Mpofu, N. (2014). HIVIAIDS Communication and Youth Behaviour in South Africa: A case of Female High School Students in the Eastern Cape Province. Unpublished doctoral thesis. University of Fort Hare, Alice, South Africa

National Institute of Allergy and Infectious Diseases (2001). Workshop summary: Scientific evidence on condom effectiveness for sexually transmitted disease prevention. National Institutes of Health

Nozipho D. (2007, 10 May).Khomanani back on track. Accessed May 7, 2014 fromhttp://www.southafrica.info/about/health/khomanani100507.htm\#.U2ptAlc9T8U

Nzioka, C. (1996). Lay perceptions of risk of HIV infection and the social construction of safer sex: Some experiences from Kenya. AIDS Care, 8, 565-579

Oyero, O. S. (2007).Communication for development in Africa: Towards a psychomanagement paradigm. Lagos Papers in English Studies. Vol. 2: 228-237. Available at http://www.artslasu.org/journal_eng/contents/vol_2/oyero2.pdf. Published by Department of English, Lagos State University, Lagos.

Peltzer, K., Parker W. Mabaso, M., Makonko, E., Zuma, K. \& Ramlagan, S. (2012). "Impact of National HIV and AIDS Communication Campaigns in South Africa to Reduce HIV Risk Behaviour," The Scientific World Journal, vol., Article ID 384608, 6 pages http://dx.doi.org/10.1100/2012/384608

SABC, 2013, Thursday 17 January 2013 13:13 ) Mixed reactions to teen consensual sex ruling.http://www.sabc.co.za/news/a/c387 a5804e36eec9a683b7f251b4e4e2/Mixed-reactions-to-teen-consensual-sex-ruling-

Sadmon, (n. d.) Khomanani Programme. Sadmon Project and Consulting Profile "Thinking Out of The Box". Accessed May 28, 2014 fromhttp://www.sadmon.com/Khomanani_programme.html

Salawu, A. (2004). Beyond entertainment and marketing of condom: A review of the impact of drama for the prevention of HIVIAIDS in Nigeria. Journal of Social and Policy Issues. 1(1), pp. $42-47$

Salawu, A. (2011). The paradigm of ethical development for civilized leadership in Africa. Leadership. 8(1): 17-27. DOI: 10.1177/17427 15011426961

Shisana O., T. Rehle, L. C. Simbayi, et al., (2009).South African National HIV Prevalence, Incidence, Behaviour and Communitcation Survey, 2008, HSRC Press, Cape Town, South Africa

Shisana, O, Rehle, T, Simbayi LC, Zuma, K, Jooste, S, Zungu N, Labadarios, D, Onoya, D et al. (2014) South African National HIV Prevalence, Incidence and Behaviour Survey, 2012. Cape Town, HSRC Press.

Sifris, D. \& Myhre, J. (April 6, 2014, About.Com) Soaring HIV Prevalence Paints a Dire Picture for South Africa http://aids.about. com/b/2014/04/06/soaring-hiv-prevalence-paints-a-dire-picture-for-south-africa.htm

South Africa Info (2007, 23 July). Drop in Aids rates 'a positive sign'. Accessed May 7, 2014 from http://www.southafrica. info/about/health/hivdrop-200707.htm

Success Academy for Youth (2001). Youth Summer Conference held August 14 to 19, 2001at National Stadium, Lagos, Nigeria.

The Foundation for AIDS Research,http://www.amfar.org/about-hiv-and-aids/young-people-and-hiv/young-people-and-hiv-aids/\# How_is_HIV_Spread?

Thom, A. \& Cullinan, K., (2010, April 20) (Health-e) South Africa: Khomanani Shambleshttp://allafrica.com/stories/201004200298.html 